\title{
Study of Coordination Characteristics of Some Metal Complexes of 2- Thiouracil by Infrared Spectroscopy
}

\author{
P. Jacquline Rosy ${ }^{*, 1}$, S. Kalyanasundharam ${ }^{2}, K_{\text {. Santhanalakshmi }}{ }^{1}$, \\ S. Muthukumar ${ }^{1}$, P. Manivannan ${ }^{1}$ \\ ${ }^{1}$ Department of chemistry, I.F.E.T College of Engineering, Gangarampalayam, \\ Villupuram, India- 605108 \\ ${ }^{2}$ Department of chemistry, Poompuhar College (Autonomous), \\ Melaiyur, India - 609107 \\ *E-mail address: jacquline.rosy @yahoo.com
}

Keywords: 2-Thiouracil; pyrimidine thione complexes; infrared spectroscopy

\begin{abstract}
The infrared spectra of 2-Thiouracil (Thu) have been recorded in the region $4000-400 \mathrm{~cm}^{-1}$. The assignments of fundamental frequencies have been proposed on the basis of assignments in related molecules. Correlation of vibrational assignments with those of related molecules have been pointed out.

The metal ion interactions of Thu with $\mathrm{Cd}$ (II), $\mathrm{Hg}$ (II), $\mathrm{Cu}$ (II), and $\mathrm{Zn}$ (II) bromides have been investigated by infrared spectroscopy. The results are consistent with the bonding of ligands through sulphur in all the complexes. The vibrational frequencies of metal complexes of 2Thiouracil are correlated with the spectral data of other structurally related pyrimidine thione complexes.
\end{abstract}

\section{INTRODUCTION}

Coordination chemistry is undoubtedly the most active research area in inorganic chemistry. Several thousands of coordination complexes have been synthesized and investigated during the past few decades. Ever since the importance of coordination phenomenon in biological processes was realized, lot of metal containing macromolecules have been synthesized and studied to understand the role of these ligands in biological systems, and they also contribute to the development of new metal-based chemotherapeutic agents. These have resulted in the emergence of an important branch of inorganic chemistry viz. bioinorganic chemistry because in several cases, the metal chelates have been found to be more antimicrobial than the chelating agents themselves [1].The importance of pyrimidine derivatives arises from their biological, medicinal and agricultural applications [2-4]. Metal complexes of pyrimidine have been extensively studied in recent years owing to their great variety of biological activity ranging from antimalarial, antibacterial, antitumor, antiviral activities etc. [5-6]. The use of Uracil, Thiouracil, and Pyrimidine thiones in the process of biochemical importance and providing bonding sites for metal ions has simulated much research [7]-[10]. Pyrimidine 2-thione is present in soluble ribonucleic acid [11], Pyrimidine 2-thione (pymt) and its derivatives find importance as antitumour and antithyroid agents [12]. Like the thiobases, 2thiouracil, 4-thiouracil and 2-thiocytosine (whose molecular) structures are closely related to pyrimidine thiones (pymt) and 4, 6- Dimethyl Pyrimidine-2-thione (dimpymt), under certain conditions inhibit RNA synthesis leading to antitumour activity [13]. Numerous sulphur substituted pyrimidines have found applications as clinically useful drugs. It has been observed that 2-thiouracil inhibits biosynthesis of thyroid hormone. It is therefore considered interesting to study the infrared spectrum of the 2-Thiouracil and its donor characteristics with some transition metal ions. The selection of group IIB metal ions $(\mathrm{Cd}, \mathrm{Hg})$ is of special significance. They being toxic, pyrimidine thiones and Thiouracil have been found to have antitumour and antithyroid activity, it is considered 
interesting to study their metal complexes. Also the selections of these metal ions were made by their known preference for sulphur donors. The interaction of metal ions with nucleobases is of great interest because of their relevance to the essential, medical or toxic bioactivity of metal, where nucleobases molecule can coordinate as exogenous ligands in metalloproteins, functions as cofactors in the enzymatic systems and construct important cell structures (RNA).

\section{MATERIALS AND METHODOLOGY}

\section{A. Preparative Procedures:}

2-Thiouracil was from Aldrich chemical and used as such without any purification.The solvent ethanol was purified following the procedure of Vogel [14].

B. Metal Salts:

$\mathrm{CdBr}_{2}, \mathrm{CuBr}_{2}, \mathrm{HgBr}_{2}$, and $\mathrm{ZnBr}_{2}$ are all AR grade chemicals (E-merck).

\section{Metal Complexes:}

Cadmium bromide ( 2 millimole) was treated with 2-Thiouracil in 1:2 molar proportion in hot ethanol with constant stirring and further refluxed for 1 hour, and cooled. The separated complex was filtered of under nitrogen, washed with ethanol and ether and dried in vacuum.

The copper, mercury and zinc complexes were obtained by the same procedure but using cold ethanol solution. Metal analysis for cadmium, mercury and copper were carried out following the procedure of Vogel [14].

Cadmium, Copper and Zinc: They were estimated by EDTA titration employing a few drops of xylenol orange indicator and hexamine as buffer.

Mercury: The solution was allowed to react with nitric acid to oxidize $\mathrm{Hg}$ (I) if any to $\mathrm{Hg}$ (II) state. The solution was then neutralized by sodium hydroxide and the metal estimated by EDTA titration using Eriochrome Black-T as an indicator.

\section{Spectral measurements:}

A Bruker IFS-66V FT IR Spectrophotometer was employed to record the complexes of 2Thiouracil in infrared spectrum $\left(4000-400 \mathrm{~cm}^{-1}\right)$ of the solid samples as $\mathrm{KBr}$ pellets available at Indian Institute of Technology, Madras.

\section{RESULTS AND DISCUSSIONS}

The assignments given in the TABLE I were established after careful consideration of the assignments available for related molecules like Pyrimidine-2-thione [15],[22], 4,6-dimethyl pyrimidine-2-thione [15], 1,4,5,6-tetrahydropyrimidine-2-thione [15], 2-pyrimidone [16], 2chloropyrimidine [17], pyrimidine [18], cytosine [19], thiocytosine and other related compounds. The general procedure followed for empirical assignments of thioureide frequencies are (i) $\mathrm{N}$ deuteration studies (ii) S-methylation studies (iii) selenation technique (iv) study of polarization characteristics of infrared bands in the oriented crystalline samples [20].

\section{A. N-deuteration studies:}

The thiouriede N-H is replaced by heavier isotope deuterium. The infrared spectrum of ndeuteration labeled compound is compared with unlabeled N-H compound. The perturbation of frequencies consequent to N-deuteration is considered while making thiouriede N-H assignments. Usually the N-H stretching modes are highly sensitive to deuterium labeling. They show pronounced lowering of frequencies.

\section{B. S-Methylation studies:}

The thiocarbonyl group $\mathrm{C}=\mathrm{S}$ is $\mathrm{S}$-methylated. The infrared spectra of S-methylated compounds registers red shift of over $40 \mathrm{~cm}^{-1}$ for $\mathrm{C}=\mathrm{S}$ stretching mode, consequent to $\mathrm{S}$ methylation due to decreased $\mathrm{C}=\mathrm{S}$ bond order. 
TABLE 1. SOME CHARACTERISTICS INFRARED FREQUENCIES $\left(\mathrm{cm}^{-1}\right)$ OF 2THIOURACIL

\begin{tabular}{|c|c|}
\hline Thu frequencies & Main assignment \\
\hline 3084 vs & \multirow{2}{*}{ CH stretching } \\
\hline $3050 \mathrm{w}$ & \\
\hline $2922 \mathrm{w}$ & \multirow{2}{*}{ NH stretching } \\
\hline $2910 \mathrm{w}$ & \\
\hline $1685 \mathrm{vs}$ & $\mathrm{C}=\mathrm{O}$ stretching + ring stretching \\
\hline $1628 s$ & \multirow{2}{*}{ Ring stretching (CN stretching ) } \\
\hline $1562 \mathrm{~ms}$ & \\
\hline $1450 \mathrm{~ms}$ & $\mathrm{NH}$ bending (in plane) \\
\hline $1421 \mathrm{~ms}$ & \multirow{3}{*}{ Ring stretching } \\
\hline 1239 vs & \\
\hline $1213 \mathrm{vs}$ & \\
\hline $1393 \mathrm{~s}$ & CH-bending \\
\hline $1175 \mathrm{~s}$ & $\mathrm{C}-\mathrm{H}$ bending ring stretching \\
\hline $1070 \mathrm{~s}$ & Ring deformation \\
\hline $895 \mathrm{~s}$ & $\mathrm{~N}-\mathrm{H}$ bending (out of plane) \\
\hline $995 \mathrm{~m}$ & Ring breathing \\
\hline $760 \mathrm{~ms}$ & $\mathrm{C}=\mathrm{S}$ stretching \\
\hline $648 \mathrm{~s}$ & $\mathrm{C}=\mathrm{O}$ (in plane bending) \\
\hline $526 \mathrm{~s}$ & $\mathrm{C}=\mathrm{O}$ (out of plane bending) \\
\hline $547 \mathrm{~s}$ & $\mathrm{C}=\mathrm{S}$ (in plane bending) \\
\hline
\end{tabular}

\section{Selenation technique:}

The sulphur atom is replaced by selenium and the infrared spectra of selenium with $\mathrm{C}=\mathrm{Se}$ and compound with $\mathrm{C}=\mathrm{S}$ are compared. Due to mass effect the $\mathrm{C}=\mathrm{Se}$ stretching frequency is lowered compared to $\mathrm{C}=\mathrm{S}$. this selenation technique has been used to identity $\mathrm{C}=\mathrm{S}$ and other thiouriede vibrations [21]-[22].

\section{Polarization studies:}

Study of polarized infrared spectra of oriented crystalline samples is useful for making vibrational assignments in solids and in the factor group and site group analysis of crystals and also the polarization characteristics of $\mathrm{C}=\mathrm{S}$ stretching frequencies of thiocarbonyl compounds. The use of Raman depolarization measurements in the classification of molecular vibrations is also known.

Using the above aids the vibrational spectra of pyrimidine-2-thione have been well studied by Shanmugam and Sathyanarayana [20]-[23]. The problematic $\mathrm{C}=\mathrm{S}$ stretching frequencies in these related molecules have been assigned. Using these data assignments of 2-Thiouracil is attempted here.

\section{E. Comparison of the assignments:}

The assignments of 2-Thiouracil (Thu) (in TABLE I) are compared with those in related molecules such as pyrimidine, 2-pyrimidone, pyrimidine-2-thione, 4, 6-dimethyl pyrimidine-2thione, 1, 4, 5, 6-tetrahydropyrimidine-2-thione in (TABLE II) to note the internal consistency in the assignments. The data generally appear to be a satisfactory representation. The assignments differ in some cases; however, salient features of the comparison are discussed below. The absence of band around $2550 \mathrm{~cm}^{-1}$ indicated the absence of S-H vibrations. Thus the thione tautomer of 2Thiouracil (Thu) seems to be predominant in the solid state. It has been observed most of the thiopyrimidine derivatives exist in thione form in the solid state. 


\section{F. $N$-H group frequencies:}

The N-H stretching frequency of 2-Thiouracil (Thu) assigned around $2922 \mathrm{~cm}^{-1}$, compatible in assignments made for Pyrimidine-2-thione (pymt) and 4,6- Dimethyl Pyrimidine-2thione(dimpymt) around this region (TABLE II).

Table 2. COMPARISON OF THU INFRARED FREQUENCIES $\left(\mathrm{cm}^{-1}\right)$ WITH RELATED MOLECULES

\begin{tabular}{|c|c|c|c|c|c|c|c|}
\hline Pyrimidine & $\begin{array}{l}\text { Pyrimidine- } \\
\text { 2-one }\end{array}$ & $\begin{array}{l}1,4,5,6- \\
\text { tetrahydro } \\
\text { pyrimidine-2- } \\
\text { thione }\end{array}$ & $\begin{array}{l}\text { 4,6- Dimethyl } \\
\text { Pyrimidine-2- } \\
\text { thione }\end{array}$ & $\begin{array}{l}\text { Pyrimidine-2- } \\
\text { thione }\end{array}$ & $\begin{array}{l}\text { 5,6-diamino- } \\
\text { 2-thiouracil }\end{array}$ & 2-Thiouracil & $\begin{array}{l}\text { Main } \\
\text { Assignment }\end{array}$ \\
\hline 3095 & 3070 & 2960 & 2960 & 3080 & _- & 3080 & C-H stretching \\
\hline 3083 & $\begin{array}{l}3019 \\
2820\end{array}$ & 3160 & 3060 & $\begin{array}{l}2960 \\
3050\end{array}$ & $\begin{array}{l}2979 \\
2896\end{array}$ & 2922 & N-H stretching \\
\hline- & 1540 & 1560 & - & 1565 & 1579 & 1562 & C-N stretching \\
\hline- & 1648 & - & - & - & 1638 & 1685 & $\mathrm{C}=\mathrm{O}$ stretching \\
\hline 1146 & 1618 & - & 1620 & 1608 & 1638 & 1628 & Ring stretching \\
\hline 1071 & 1230 & 1345 & 1590 & 1420 & 1456 & 1450 & $\mathrm{~N}-\mathrm{H}$ bending \\
\hline- & $\begin{array}{l}1350 \\
1230\end{array}$ & - & 1330 & 1335 & 1376 & 1393 & $\mathrm{C}-\mathrm{H}$ bending \\
\hline- & 1198 & - & 1210 & 1210 & 1042 & 1070 & $\begin{array}{l}\text { Ring deforming } \\
+\mathrm{C}-\mathrm{H} \\
\text { bending+C- } \\
\text { Xstretching }\end{array}$ \\
\hline- & 1160 & - & 1190 & 1182 & - & 1175 & $\begin{array}{l}\mathrm{CH} \text { bending ring } \\
\text { stretching }\end{array}$ \\
\hline- & - & - & 990 & 965 & 997 & 995 & Ring breathing \\
\hline- & 952 & 635 & 590 & 965 & 892 & 895 & $\begin{array}{l}\mathrm{N}-\mathrm{H} \text { bending } \\
\text { (out of plane) }\end{array}$ \\
\hline- & 636 & - & - & - & 649 & 648 & $\begin{array}{l}\mathrm{C}=\mathrm{O} \text { (inplane } \\
\text { bending) }\end{array}$ \\
\hline - & _- & 642 & 850 & 750 & 623 & 760 & $\mathrm{C}=\mathrm{S}$ stretching \\
\hline- & - & 340 & 520 & 470 & 551 & 547 & $\begin{array}{l}\mathrm{C}=\mathrm{S} \\
\text { bending(inplane) }\end{array}$ \\
\hline- & 513 & - & - & - & 478 & 526 & $\begin{array}{l}\mathrm{C}=\mathrm{O} \text { (out of } \\
\text { plane bending) }\end{array}$ \\
\hline
\end{tabular}

\section{G. $C=S$ Vibrations:}

A band of interest in 2-Thiouracil is that arising from $\mathrm{C}=\mathrm{S}$ stretching mode. A medium strong band around $760 \mathrm{~cm}^{-1}$ may be attributed as arising predominantly from $\mathrm{C}=\mathrm{S}$ stretching mode in 2Thiouracil. A similar low frequency band has been assigned in the case of pyrimidine-2-thione (750 $\mathrm{cm}^{-1}$ ) [21]-[22]. The nature of $\mathrm{C}=\mathrm{S}$ stretching mode of Thu is akin to that in alkyl thionamides [24][26]. It is found consistent with the corresponding frequency in thiones $\left(720 \mathrm{~cm}^{-1}\right)$ and that of tetrahydropyrimidine thione $\left(642 \mathrm{~cm}^{-1}\right)$ [21]-[22]. The $\mathrm{C}=\mathrm{S}$ stretching mode is thus sensitive to molecular environment. Recently the vibrational spectra of 4, 6-diamino-2-thiouracil (DA2Thu) have been studied by Jeyanthi [27] and $\mathrm{C}=\mathrm{S}$ stretching frequency assigned around $623 \mathrm{~cm}^{-1}$. The $\mathrm{C}=\mathrm{S}$ bending fundamentals (in plane bending) may be assigned at $547 \mathrm{~cm}^{-1}$ compatible with that of $520 \mathrm{~cm}^{-1}$ of dimpymt. 


\section{H. Metal Complexes:}

The complexes have stoichiometry $\mathrm{ML}_{2} \mathrm{Br}_{2}(\mathrm{M}=\mathrm{Cd}, \mathrm{Hg}, \mathrm{Cu}, \mathrm{Zn})$. 2-Thiouracil (Thu) is a multisite ligand. Thiocarbonyl sulphur, pyrimidine ring nitrogens, carbonyl oxygen may have the possibility of coordinating with the metal ions. However the infrared spectral data indicate only the thiocarbonyl sulphur involves in coordination as discussed below.

\section{Infrared spectra of metal complexes:}

Selected infrared frequencies of metal complexes of 2-Thiouracil (Thu) are assembled in TABLE I. The shifts in the infrared band positions of thiourea derivatives consequent to coordination have been discussed by Lane et al [28]. The free ligand may be considered to exist in two resonance forms as shown below.

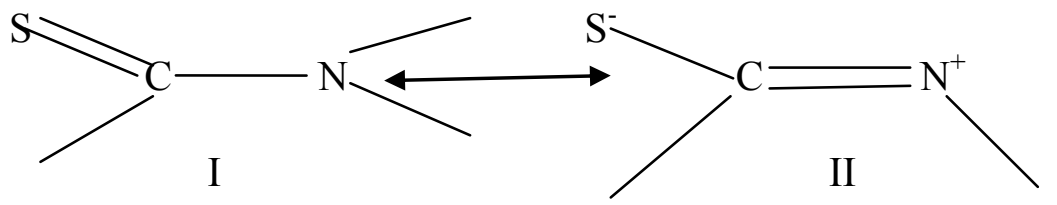

Greater contribution from the polar form (II) is predicted. In the complexes of thiourea derivatives when coordinated through sulphur one looks for (i) a decrease in $\mathrm{C}=\mathrm{S}$ stretching frequency and a concomitant increase in the $\mathrm{C}-\mathrm{N}$ stretching frequency in the spectra of the metal complexes compared to that in the free ligand spectrum and (ii) appearance of new bands due to metal-sulphur stretching vibrations. The coordination of ligands through nitrogen atom would require a downward shift in the sensitive N-H stretching frequency by $200-300 \mathrm{~cm}^{-1}$. However in the spectra of complexes of Thu, there is no shift in the N-H frequencies. This suggests that the protonated nitrogen as the coordinating atom can be excluded in all the complexes discussed here. Also the carbonyl frequencies of the free ligand are not much affected in the infrared spectra of metal complexes investigated in the present work indicating their non-involvement in bonding with metal ions. In the spectra of Cadmium, Copper, Zinc and Mercury bromide complexes of Thu the stretching frequency assigned at $760 \mathrm{~cm}^{-1}$ of the ligand shows a definite red shift of $20-25 \mathrm{~cm}^{-1}$ due to decreased bond orders consequent to coordination with sulphur atom. The in plane bending $\mathrm{C}=\mathrm{S}$ frequency assigned at $547 \mathrm{~cm}^{-1}$ show marginal increase in the spectra of metal complexes as expected (TABLE III).

The C-N stretching frequency assigned at $1562 \mathrm{~cm}^{-1}$ of the free ligand registers a marginal increase in the spectra of complexes. Thus, it may be concluded from the spectra that in these metal complexes the ligand coordinates through sulphur. However, the low frequency metal-ligand and metal bromide vibrations, usually observed below $400 \mathrm{~cm}^{-1}$ could give much information regarding the coordination site.

\section{J. Structure of complexes:}

Cadmium, Mercury, Copper and Zinc bromide complexes may be postulated to have tetrahedral geometry as predicted in the case of metal complexes of Pyrimidine-2-thione.

TABLE 3. SELECTED INFRARED BANDS $\left(\mathrm{cm}^{-1}\right)$ OF THU-METAL BROMIDE COMPLEXES

\begin{tabular}{|l|l|l|l|l|l|l|l|}
\hline Complex & $\begin{array}{c}\text { N-H } \\
\text { stretching }\end{array}$ & $\begin{array}{c}\mathrm{C}-\mathrm{N} \\
\text { str }\end{array}$ & $\begin{array}{c}\mathrm{C}=\mathrm{O} \\
\text { str }\end{array}$ & $\begin{array}{c}\mathrm{C}=\mathrm{S} \\
\text { str }\end{array}$ & $\begin{array}{c}\mathrm{C}=\mathrm{O} \\
\text { inplane } \\
\text { bending }\end{array}$ & $\begin{array}{c}\mathrm{C}=\mathrm{S} \\
\text { inplane } \\
\text { bending }\end{array}$ & $\begin{array}{c}\mathrm{C}=\mathrm{O} \\
\text { outplane } \\
\text { bending }\end{array}$ \\
\hline $\mathrm{L}-\mathrm{Thu}$ & $2910 \mathrm{w}$ & $1562 \mathrm{~ms}$ & $1685 \mathrm{~ms}$ & $760 \mathrm{~s}$ & $648 \mathrm{~s}$ & $547 \mathrm{~s}$ & $526 \mathrm{~s}$ \\
\hline $\mathrm{CdL}_{2} \mathrm{Br}_{2}$ & $2924 \mathrm{~ms}$ & $1563 \mathrm{~ms}$ & $1683 \mathrm{~ms}$ & $735 \mathrm{~ms}$ & $647 \mathrm{~ms}$ & $546 \mathrm{~ms}$ & $526 \mathrm{~s}$ \\
\hline $\mathrm{HgL}_{2} \mathrm{Br}_{2}$ & $2926 \mathrm{~m}$ & $1566 \mathrm{~m}$ & $1683 \mathrm{~s}$ & $732 \mathrm{~ms}$ & $650 \mathrm{~ms}$ & $547 \mathrm{~s}$ & $525 \mathrm{~s}$ \\
\hline $\mathrm{CuL}_{2} \mathrm{Br}_{2}$ & $2912 \mathrm{~m}$ & $1536 \mathrm{~m}$ & $1685 \mathrm{~s}$ & $734 \mathrm{~ms}$ & $648 \mathrm{ssh}$ & $547 \mathrm{~s}$ & $526 \mathrm{~s}$ \\
\hline $\mathrm{ZnL}_{2} \mathrm{Br}_{2}$ & $2923 \mathrm{~m}$ & $1563 \mathrm{~m}$ & $1682 \mathrm{~s}$ & $735 \mathrm{~ms}$ & $647 \mathrm{~m}$ & $546 \mathrm{~s}$ & $526 \mathrm{~s}$ \\
\hline
\end{tabular}




\section{CONCLUSION}

It seemed appropriate to make a few remarks regarding the work described in the earlier. The vibrational spectra of several thiocarbonyl compounds have been supported with the aid of polarized infrared and Raman spectral data and normal coordinate calculations from time to time. Thus, in the present study, correlative criteria have been made use of in making vibrational assignments. Though the assignments proposed here are qualitative and empirical, the generally good agreement in the characteristics bands suggests that the proposed assignments are a satisfactory representation. The present work on corresponding bromo complexes should add to the spectral data earlier reported and should give further supportive evidence on the coordination characteristics of the ligand.

\section{ACKNOWLEDGEMENT}

It is with deep sense of gratitude and respect that I wish to thank my research supervisor Dr.R.Shanmugam for his excellent guidance, valuable discussions and inspiration for the completion of my work.

\section{References}

[1]. Srivastava, R. S. "Pseudotetrahedral Co (II), Ni (II) and $\mathrm{Cu}$ (II) complexes of $\mathrm{N}<\sup >$ $1</$ sup $>$-(O-chlorophenyl)-2-(2', 4'-dihydroxyphenyl)-2-benzylazomethine their fungicidal and herbicidal activity." Inorganica Chimica Acta 56, 1981, pp. L65-L67.

[2]. Hung J, Werbel M." Investigations into the Synthesis of 6-Ethyl-5-(4-pyridinyl)-2,4pyrimidine- diamine as a Potential Antimalarial Agent” J Heterocycl Chem 1984, pp. 21: 74.

[3]. Rittich, Bohuslav, et al. "The antifungal activity of some aliphatic and aromatic acids." Collection of Czechoslovak chemical communications 57.5 (1992): pp, 1134-1142.

[4]. Arfmann, Hans-Adolf, and Wolf-Rainer Abraham. "Microbial reduction of aromatic carboxylic acids." ZEITSCHRIFT FUR NATURFORSCHUNG C 48 (1993): pp. 52-52.

[5]. Refat, Moamen S., Sabry A. El-Korashy, and Ahmed S. Ahmed. "A convenient method for the preparation of barbituric and thiobarbituric acid transition metal complexes." Spectrochimica Acta Part A: Molecular and Biomolecular Spectroscopy 71.3 (2008): pp. 1084-1094.

[6]. Casas J S, Castellans EE, Louce MD, Ellena J, Sanchez A, Sordo J, Taboada C. J Inorg Biochem 2006;1: pp. 1858-1860.

[7]. Abbot, John, David ML Goodgame, and Ian Jeeves. "Complexes of pyrimidine-2-thione with some bivalent metal halides of the first transition series." Journal of the Chemical Society, Dalton Transactions 7 (1978): pp. 880-884.

[8]. Battistuzzi, Raffaele, and Giorgio Peyronel. "Copper (I) complexes of neutral, deprotonated and protonated 4, 6-dimethylpyrimidine-2 (1H)-thione." Transition Metal Chemistry 3.1 (1978): pp. 345-351.

[9]. Goodgame, D. M. L., and G. A. Leach. "Complexes of 1, 4, 6-trimethylpyrimidine-2-thione with some divalent metal halides." Inorganica Chimica Acta 32 (1979): pp. 69-73.

[10]. Battistuzzi, R., and G. Peyronel. "Copper (I) and copper (II) complexes of 4, 6dimethylpyrimidine-2 (1H)-one." Spectrochimica Acta Part A: Molecular Spectroscopy 36.6 (1980): pp. 511-515.

[11]. Shefter, Eli, and Henry G. Mautner. "Acetylcholine and its thiolester and selenolester analogs: conformation, electron distribution, and biological activity."Proceedings of the National Academy of Sciences 63.4 (1969): pp. 1253-1260. 
[12]. Votruba, Ivan, Antonín Holý, and Karel Jošt. "Conversion of 2-mercaptopyrimidine into $<\mathrm{i}>$ $\mathrm{S}</ \mathrm{i}>$-(pyrimidin-2-yl)-cysteine in growing $<\mathrm{i}>$ Escherichia coli $</ \mathrm{i}>$ cells." FEBS letters 22.3 (1972): pp. 287-288.

[13]. Holý, A., I. Votruba, and K. Jošt. "S-(Pyrimidin-2-yl)-L-cysteine: Chemical synthesis and biosynthesis in Escherichia coli." Collection of Czechoslovak Chemical Communications 39.2 (1974): pp. 634-646.

[14]. A.I.Vogel, A text book of quantitative inorganic analysis, Fourth Edition (1978)

[15]. S.Anusuya, M.Phil thesis, University of Madras. (1987) unpublished.

[16]. R.Shanmugam and D.N Sathyanarayana, Indian J.Pure and Applied Physics.

[17]. Picquenard, E., \& Lautié, A. (1982) Etude par spectrométrie infrarouge et Raman de la pyrimidone-2 et de son chlorhydrate (chlorure d'oxo-2 pyrimidinium). 38 (6), pp. 641-648.

[18]. Sarma, Y. Anantharama. "Planar vibrations of 2-chloropyrimidine." Spectrochimica Acta Part A: Molecular Spectroscopy 30.9 (1974): 1801-1806.

[19]. Innes, K. K., J. P. Byrne, and I-G_Ross. "Electronic states of azabenzenes: A critical review." Journal of Molecular Spectroscopy 22.1 (1967): pp. 125-147

[20]. Innes, K. K., J. P. Byrne, and I-G_Ross. "Electronic states of azabenzenes: A critical review." Journal of Molecular Spectroscopy 22.1 (1967): pp. 125-147.

[21]. Susi, H., J. S. Ard, and J. M. Purcell. "Vibrational spectra of nucleic acid constituents-II: Planar vibrations of cytosine." Spectrochimica Acta Part A: Molecular Spectroscopy 29.4 (1973): pp. 725-733.

[22]. Shunmugam, R., and D. N. Sathyanarayana. "Raman and polarized infrared spectra of pyridine-2-thione." Spectrochimica Acta Part A: Molecular Spectroscopy 40.8 (1984): pp. $757-761$.

[23]. Shunmugam, R., and D. N. Sathyanarayana. "Vibrational Spectra of 1, 4, 5, 6-Tetrahydropyrimidine-2-Thione and-2-One." Bulletin des Sociétés Chimiques Belges 92.11-12 (1983): pp. 943-950.

[24]. Shunmugam, R., and D. N. Sathyanarayana. "Vibrational Spectra of Pyrimidine-2-Thione and Pyrimidine-2-Selone." Bulletin des Sociétés Chimiques Belges93.2 (1984): pp. 121-127.

[25]. Shunmugam, R., D. N. Sathyanarayana, and A. Anagnostopoulos. "Vibrational spectra of imidazoline-2-one and of imidazoline-2-thione and its N-methyl derivative." Canadian journal of spectroscopy 28.5 (1983): pp. 150-155.

[26]. Devi, Kolar Ramakrishnaiaa Gayathri and Sathyanarayana, Dixit Narayanarao (1980) Assignment of fundamental vibrations of. ,N'-dimethylthiourea,. In: Bulletin of the Chemical Society of Japan, 53 (10). pp. 2990-2994.

[27]. Desseyn, H. O., Aarts, A. J., Esmans, E., \& Herman, M. A. (1979). The secondary thioamide function-I. The vibrational analysis of $\mathrm{NN}^{\prime}$ dimethyl-dithiooxamide. Spectrochimica Acta Part A: Molecular Spectroscopy, 35(10), pp. 1203-1211.

[28]. K.Jeyanthi, M.Phil thesis Bharathidasan university (2004). Unpublished.

[29]. Lane, T. J., and A. Yamaguchi. "Quac hano, JV; Ryan, RA; Muzhushi, A." Infrared Studies of Methylthiourea and its Metal Complexes J. Am. Chem. Soc 81 (1959): pp. 38. 